\title{
Contributions of nursing care to women
}

\author{
Marilene Loewen Wall' \\ ' Universidade Federal do Paraná, Department of Nursing. Curitiba, Paraná, Brazil.
}

\section{How to cite this article:}

Wall ML. Contributions of nursing care to women. Rev Bras Enferm [Internet]. 2018;71(Suppl 3):1203-4.

[Thematic Issue: Health of woman and child] DOI: http://dx.doi.org/10.1590/0034-7167-201871sup301

The situation of women and, particularly, the problems concerning their lives deserve special care by health professionals, society and mass media, in order to change their situation and boost improvements due to the condition where women were inserted decades ago and nowadays.

The pregnancy-postpartum circle may be the most dramatic and exciting experience in the life of a woman. This phase causes an enormous impact on the life of women and their family. Studies on modern pregnancy experience have widen its focus, extrapolating psychosocial aspects of pregnancy that may be whether an exciting and grateful experience or a phase of stress and abrupt changes not only in women's life but in the future father's life as well. Although it is known, traditionally, the physical aspect of pre-natal evaluation has been appreciated. Little care is given to the steps of emotional development, to the characteristics of women behavior or to the way how she or the couple faces this experience.

In the puerperal period, women go through many physiological and psychological adjustments. The transition to maternity is abrupt, because the responsibility on caring for a child comes suddenly and sometimes the woman is not ready. Besides that, as women normally stay hospitalized for a short time, they need support and guidance, as in relation to the care of the child as to the self-care. They need a support that can be offered at home, in the outpatient or in the basic health unit.

The improvement in health conditions to women do not depends on economic, social, political or cultural affairs; the improvement depends on reinforcement, integrality and humanization in the care given by a multiprofessional team, in which each professional will count on the support of professionals that integrate health care services. From this point of view, women would transit from beneficiary to participant in the process of care.

We cheer with great satisfaction the publication of the $\mathrm{WHO}^{(1)}$, with recommendations of care during childbirth, so that the birth of a newborn is a positive experience, reinforcing what had already been recommended by several governmental policies and programs for maternal health in national and international range. The guideline highlights the importance of woman-centered care to optimize the experience of labor and delivery for her and her baby through a holistic, human rights-based approach. It proposes a global model of intrapartum care, which takes into account the complexity and diverse nature of prevailing models of care, and contemporary practice.

The Ministry of Health presents the Apice On - Improvement and Innovation in Care and Teaching in Obstetrics and Neonatology project - proposing the qualification in the care of women in different settings and phases of their life, by introducing movements for changes in traditional training, care and management models in teaching hospitals within the framework of the Rede Cegonha (The Rede Cegonha is a package of actions to ensure quality, safe and humanized care for all women). This project aims to "... to qualify care, management and training processes related to childbirth, birth and abortion in hospitals with teaching activities, incorporating a model based on scientific evidence, humanization, security and rights assurance ${ }^{\prime \prime(2)}$.

If we consider the nature of nursing as a humanistic science and as a discipline oriented to the practice, care and health, we will need to carry out research, studies and develop theoretical structures so that nursing knowledge is fostered with limits, and theoretical and practical foundations through the systematization of care and why not, for the construction of models of care and nursing theories ${ }^{(3)}$. 
In this perspective, we will be able to offer a differentiated nursing service, since we will plan singular actions, based on the needs of each woman, participating in a family and inserted in a community, observing and respecting their integrality, thus contributing to the excellence of the care provided.

\section{REFERENCES}

1. World Health Organization - WHO. WHO recommendations: intrapartum care for a positive childbirth experience [Internet]. 2018[cited 2018 Feb 20]. Available from: http://www.who.int/reproductivehealth/ publications/intrapartum-care-guidelines/en/

2. Brasil. Ministério da Saúde. Projeto Apice On. Brasilia: MS; 2017. p. 23

3. Meleis AI. Transitions theory: middle-range and situation-specific theories in nursing research and practice. New York: Springer Publishing Company; 2010. 